\title{
CARTAS, RIZOS DE LUZ RECIÉN CORTADA, SEDA COBRIZA O ALA NEGRA
}

\author{
Roland Barthes, Fragmentos de un discurso amoroso
}

—Rizábamos el rizo, nos rimábamos, y nunca se dejaba venir lo que tintó tu corazón de rubio. Pero eso sí: descamisados en nuestra bonanza, jodidos del amor para escribir, pusimos dos puntos en la mesa ni puesta ni servida de las manos, como si las dejáramos caer, tan dadas, tan quedadas, a ver si se seguían (si acaso nos seguíamos) de largo, a ver si nos tocaban hasta siempre. -El oro de tu pelo, Cenicienta, despeinado a las doce. $\mathrm{O}$ los hados padrinos y la mafia menor de sus encantos buscando sobornarte con luz, con una feria 
que me sobra

del día en que te diste.

- Qué rosa es el amor,

medio pariente

de si, la que se abre

al roce,

la que se cierra al ras

del agua, la narcisa

librando su balanza

inclinada al color,

luego al aroma

y a nada, finalmente,

marchita con su fiel

que quiso ambos.

-Total,

si me hubieras herido

como si me hirieras;

si los puñales

fueran dos, y no el colmo

de una ausencia

que le apena doler,

las rosas

serían diferentes:

por docenas, a pasto;

las rojas, apenadas

con las blancas;

las negras;

las amarillas

o las amarillas,

las cortadas

que no tocaron fondo

ni tierra.

$\mathrm{O}$ rosas. $\mathrm{O}$ amarillas. 